\title{
Effect of Social Capital on Innovation: A Mediating Role of Employee Motivation
}

\author{
Mohsen Yazdanifar \\ Faculty of Management \\ Department of MBA \\ University of Tehran \\ Tehran, Iran
}

\begin{abstract}
Enterprises' survival depends on their ability to selfreconstruct. This reconstruction regards coordinated goals with the current situation and improved methods used to achieve these goals. Companies have to improve processes of innovation and creativity in order to adapt to changes. This study tends to examine the effect of social capital on innovation with emphasis on the mediating role of employee motivation. Through a descriptive-correlational study, 196 SSO employees in Tehran were randomly recruited and were asked to fill out relative questionnaires. The validity and reliability of the questionnaires were determined by using CFA and calculating Cronbach's alpha. Data were tested by using descriptive tests (mean and standard deviation) and analytic tests (path analysis). The effect of social capital and employee motivation was positive and significant on organizational innovation $(p<0.01)$. Employee motivation had the highest direct effect on organizational innovation (0.59). Findings imply the effect of variables on organizational innovation. Using these results, SSO planners and managers can improve organizational innovation.
\end{abstract}

Keywords-social capital; employee motivation; organizational innovation

\section{INTRODUCTION}

Innovation is an important issue for people, institutions and societies, because of its association with flexibility and production. Innovation and creativity are two of the most important factors of growth and progress in competitive environment. Organizational innovation refers to creation or selection of an idea or behavior and its successful implementation [1]. Creativity and innovation are necessary for the survival of any enterprise. It is essential to examine effective variables on organizational innovation and recommendations in this area [2]. One of the effective variables on organizational innovation is employee motivation. Motivation is an important, yet vague concept in work and organizational science. Employee motivation is considered a main factor of organizational innovation [3].

Motivation is an internal factor which drives employees. Its definitions vary. Motivation is a psychological process which leads to arousal, direction, intensity and persistence of behavior. Given the importance of tacit knowledge and its utilization to establish effective communications in order to perform activities better, a main factor for using tacit and explicit knowledge of employees for innovation is motivation and enthusiasm for participation in the company's development [4]. Another influential variable on innovation is social capital. Social capital is useful for people, groups and organizations which have it in abundance. In fact, high quality of social capital helps businesses improve their performance and stable behavior [5]. Proper social capital enables management to resist more successfully against competition. High quality of social capital helps organizations improve their performance and stable behavior [6]. The current study tends to examine the effect of social capital on organizational innovation focusing on the mediating role of employee motivation.

\section{THEORETICAL FRAMEWORK}

\section{A. Social Capital}

If physical capital exists in the building and generating equipment, financial capital is what a person has in the bank (money), human capital exists in the mind (education and skills), social capital exists in relations or networks. Social capital exists neither in people nor in physical tools of production. Bourdieu introduced one of the most powerful social analyses in contemporary sociology. He had an instrumental view of social capital and focused on two aspects: 1) individual benefits from participating in the group and 2) intentional social communications to provide greater access to these resources and individual benefit. Social capital results from: mutual trust, mutual social interaction, social groups with a sense of collective identity, a sense of shared picture of the future, and teamwork. Through an organizational approach, two forms of social capital were identified: intra-organizational social capital and extra-organizational social capital. Network structure and relational aspects of social capital tended to be incorporated to this approach. Using these two types of social capital, an enterprise can collect and transform its intellectual capital into a competitive advantage. Through an organizational approach, authors in [7] defined three dimensions of intraorganizational social capital including cognitive, relational and structural dimensions:

Structural dimension: structural dimension refers to properties of social systems and networks of relationships as a 
whole. This term describes the configuration or non-personal condition of connections between people or units. In other words, this dimension refers to the general pattern of communications between the members of the organization - i.e. who is available and how he is available, or whether people in the organization know each other [7]. This dimension indicates the extent to which people communicate in the enterprise [8]. The most important aspects of this dimension are the presence or absence of network links between members. This dimension describes the pattern of communications in terms such as intensity, connection and hierarchy and organization [7]. Overall, it focuses on whether people communicate with each other [8].

Relational dimension: relational dimension describes the type of personal relationships with others expanded through a history of interactions. This concept focuses on certain relationships, such as respect and friendship, which influence behavior. Through these personal relationships, people meet social incentives such as socialization, ratification and prestige. Trust and trustworthiness, norms and guarantees, requirements and expectations, identity and identification are the most important aspects of this dimension [7]. Unlike structural dimension which emphasizes on quantity of relationships, this dimension focuses on nature and quality of relationships [8].

Cognitive dimension: cognitive dimension refers to resources which provide representations, interpretations and shared meaning systems among members, such as common codes, language, and jokes [7]. In other words, cognitive dimension deals with the extent to which employees share a vision and common understanding within a social network. Therefore, as relational dimension, cognitive dimension of social capital deals with the nature of relationships between people. Unlike relational dimension, however, this dimension focuses on whether quantity and quality of relationships have a cognitive component for members [8]. Two components of this dimension include common goals and a common culture among members of the organization (a set of institutionalized behavioral norms) [9].

\section{B. Organizational Innovation}

In general, the term organizational innovation refers to the emergence or acceptance of a behavior or new idea. Innovation involves creation, adoption and implementation of new ideas in processes, new products and services or marketing. In fact, organizational innovation is defined as implementation of new ideas, whether it comprises products, services, processes, management or marketing systems. Enterprises follow different innovations to achieve competitive advantage, for example, innovation in goods and services, innovation in strategy and structure, innovation in culture and technology. These innovations are manifested in various forms and are followed by certain advantages. The strategic advantage of types of innovation is presented in Table I. Author in [10] distinguishes two types of innovation: Technical innovation and administrative innovation. Technical innovation includes new processes, new products and services. Administrative innovation refers to new policies, procedures and forms [10]. Since this model is used in the current study, these dimensions are described here (Figure 1). Product innovation: product innovation provides a means of production [11]. Product innovation refers to development of new and improved products and services. In fact, product innovation shows the extent to which an enterprise is providing new services, allocating financial resources to research and development and so on. Process innovation: process innovation provides a tool in order to maintain and improve quality and cost saving [11]. It involves adoption of new or improved methods of production, distribution or service delivery. In fact, process innovation is the extent to which an enterprise uses new technologies and experiments new ways of doing things. Administrative innovation: administrative innovation refers to new procedures, policies and organizational forms [11] and involves changes which influence policies, resource allocation and other factors related to the social structure of the organization. In fact, administrative innovation is the extent to which managers use modern management systems.

TABLE I. STRATEGIC ADVANTAGE OF INNOVATION TYPES

\begin{tabular}{|c|c|}
\hline Type of innovation & Strategic advantage \\
\hline Novelty & Offering a new product or service \\
\hline Promotion of competence & Rewriting the rules of the competitive game \\
\hline Complexity & Keeping entry barriers high \\
\hline Robustness & $\begin{array}{c}\text { Improving the basic model by extending its } \\
\text { life and reducing overall cost }\end{array}$ \\
\hline $\begin{array}{c}\text { Continuous incremental } \\
\text { innovation }\end{array}$ & Continuous improvement in performance \\
\hline
\end{tabular}

\section{Job Motivation}

Job motivation is defined as a desire to achieve goals related to difficult and socially approved jobs. Author in [12] considers job motivation as a series of energizing forces which originate from within and beyond a person and begin workrelated behavior and determine its shape, intensity, direction and persistence. Author in [13] defined job motivation as one's willingness to exercise and keep trying to achieve organizational goals. He believes that job motivation is a set of psychological processes which influence allocation of personal resources to achieve those goals. This influences effectiveness and productivity. Job motivation exists when personal goals align with organizational goals. Motivation and cognition are internal regulators of human actions. Four points are noted in relation to motivation of certain behaviors: 1) Motivation has a strong and difficult aspect of guiding. 2) People work harder when they are motivated. Motivation leads to endeavor. 3) Motivation leads to persistence. 4) Motivation leads to task strategies, namely behavioral patterns produced in order to achieve a particular goal [12].

\section{Conceptual Model}

Considering the theoretical framework, the conceptual model is depicted in Figure 2. This model considers social capital as an independent variable, employee motivation as mediating variable and organizational innovation as dependent variable. Therefore, the hypotheses can be written as: H1: Social capital has a positive effect on employee motivation, $\mathrm{H} 2$ : Employee motivation has a positive effect on organizational innovation, H3: Social capital has a positive effect on organizational innovation. 


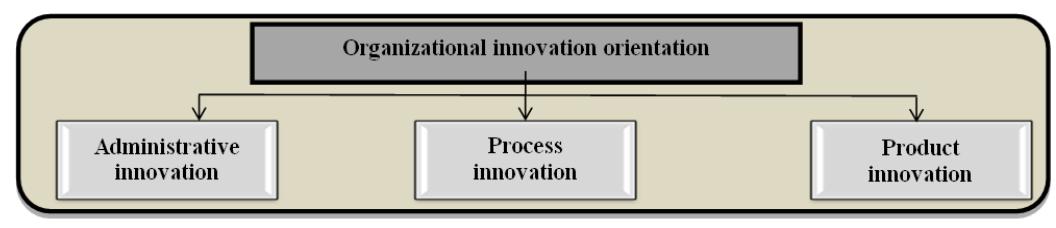

Fig. 1. Components of organizational innovation



Fig. 2. Conceptual model

\section{MATERIALS AND METHODS}

The studied population included all the employees of the Social Security Organization (SSO) in Tehran $(\mathrm{N}=400)$. Simple random sampling was used in this study $(\mathrm{n}=196)$. Questionnaires were used to collect the data required for analysis. The questions were measured on a 5-point Likert scale from strongly disagree to strongly agree. The questionnaire was distributed among SSO employees. Out of 196 questionnaires, 190 were completely responded and further analyzed and 6 questionnaires were excluded from analysis because many questions were not answered. Confirmatory factor analysis (CFA) was used to ensure the validity of the instruments.

Table II lists the CFA findings. These findings show factor loadings of cognitive dimension (0.71), structural dimension $(0.66)$ and relational dimension $(0.57)$ on social capital $(p<0.01)$ as significant. Moreover, findings show factor loadings of administrative dimension (0.74), product dimension $(0.69)$ and process dimension $(0.54)$ on organizational innovation. In addition, factor loadings of the questions 1 to 15 related to employee motivation are significant $(p<0.01)$. Furthermore, Cronbach's alpha suggests good reliability of the questionnaire. Table III lists fit indexes related to constructs. This Table shows the acceptable and estimated values for each construct. The results suggest that fit indexes of social capital, employee motivation and organizational innovation are acceptable.

\section{METHODOLOGY}

Social capital: a 24-item questionnaire was developed to measure social capital based on questionnaires developed in [7]. In this questionnaire, 7 items measure structural dimension, 11 items measure relational dimension and 6 items measure cognitive dimension. Organizational innovation: a 17-item questionnaire was developed to measure organizational innovation based on questionnaires developed in [10]. In this questionnaire, 7 items measure product innovation, 6 items measure process innovation and 4 items measure administrative innovation. Job motivation: this study used MPS index to measure employee motivation. Based on this index, attitude of employees to their current job in the organization is formed of various aspects (diversity of skills, job identity, significance, autonomy, feedback). All questions are measured on a 5-point Likert scale from strongly disagree to strongly agree.

TABLE II. CFA RESULTS

\begin{tabular}{|c|c|c|c|c|}
\hline \multirow[t]{2}{*}{ Variable } & \multirow[t]{2}{*}{$\alpha$} & \multicolumn{3}{|c|}{ Factors loadings on constructs } \\
\hline & & $\begin{array}{c}\text { Social } \\
\text { capital }\end{array}$ & $\begin{array}{l}\text { Organizational } \\
\text { Innovation }\end{array}$ & $\begin{array}{c}\text { Employee } \\
\text { motivation }\end{array}$ \\
\hline Social capital & 0.87 & & & \\
\hline Structural dimension & & 0.66 & & \\
\hline Relational dimension & & 0.57 & & \\
\hline Cognitive dimension & & 0.71 & & \\
\hline $\begin{array}{c}\text { Organizational } \\
\text { Innovation }\end{array}$ & 0.91 & & & \\
\hline Product & & & 0.69 & \\
\hline Process & & & 0.54 & \\
\hline Administrative & & & 0.74 & \\
\hline Employee motivation & 0.80 & & & \\
\hline M 1 & & & & 0.69 \\
\hline M 2 & & & & 0.75 \\
\hline M 3 & & & & 0.65 \\
\hline M 4 & & & & 0.58 \\
\hline M 5 & & & & 0.62 \\
\hline M 6 & & & & 0.60 \\
\hline M 7 & & & & 0.72 \\
\hline M 8 & & & & 0.66 \\
\hline M 9 & & & & 0.63 \\
\hline M 10 & & & & 0.59 \\
\hline M 11 & & & & 0.78 \\
\hline M 12 & & & & 0.58 \\
\hline M 13 & & & & 0.64 \\
\hline M 14 & & & & 0.71 \\
\hline M 15 & & & & 0.60 \\
\hline
\end{tabular}

TABLE III. FIT INDEXES CALCULATED FOR CFA

\begin{tabular}{|c|c|c|c|}
\hline Index & Social capital & Innovation & Motivation \\
\hline $\boldsymbol{\chi} \mathbf{2} / \mathbf{d f}$ & 3.22 & 2.85 & 1.57 \\
\hline (NFI) & 0.95 & 0.92 & 0.94 \\
\hline (NNFI) & 0.94 & 0.95 & 0.98 \\
\hline (CFI) & 0.94 & 0.96 & 0.96 \\
\hline (GFI) & 0.92 & 0.93 & 0.96 \\
\hline (AGFI) & 0.95 & 0.94 & 0.98 \\
\hline (RMSEA) & 0.047 & 0.051 & 0.068 \\
\hline
\end{tabular}

\section{RESULTS}

Table IV lists the results related to demographic variables. Once descriptive indexes were calculated, path analysis was 
used to examine causal relationships between variables. Moreover, SPSS23 and LISREL8 were used to analyze data. Analysis of causal models is based on the correlation matrix. Table $\mathrm{V}$ shows the correlation matrix, the mean and standard deviation of the variables. As shown in Table V, social capital $(\mathrm{r}=0.47)$ and employee motivation $(\mathrm{r}=0.51)$ have the highest positive and significant correlation with organizational innovation $(\mathrm{p}<0.01)$. Figure 3 shows the fitted model; the numbers on paths are standardized parameters. According to Figure 3, all paths are significant $(\mathrm{p}<0.01)$. Since this study tended to examine the effect of social capital on organizational innovation by focusing on the mediating role of employee motivation using path analysis, Table VI lists coefficients of direct effect, indirect effect and total effect and significance level of variables. As shown in Table VI, direct effect of social capital $(\beta=0.51)$ is positive and significant on employee motivation $(p<0.01)$. Direct effect of social capital $(\beta=0.42)$ is positive and significant on organizational innovation $(\mathrm{p}<0.01)$. Direct effect of employee motivation $(\beta=0.59)$ is positive and significant on organizational innovation $(p<0.01)$. Indirect effect of social capital $(\beta=0.11)$ is positive and significant on organizational innovation $(\mathrm{p}<0.01)$. Table VII lists fit indexes of path analysis model. According to Table VII, $\chi^{2} / \mathrm{df}=1.53$, GFI $=0.96$, AGFI $=0.98$ and $\mathrm{RMSEA}=0.021$ are good. Thus, the model is well fitted to data.

TABLE IV. DEMOGRAPHIC FINDINGS

\begin{tabular}{|c|c|c|}
\hline Variable & N & \% \\
\hline Gender & & \\
\hline Male & 137 & 72.2 \\
\hline Female & 53 & 27.8 \\
\hline Age & & \\
\hline $\mathbf{2 5 - 3 1}$ & 80 & 42.1 \\
\hline $\mathbf{3 1 - 3 5}$ & 65 & 34.2 \\
\hline $\mathbf{3 6 - 4 0}$ & 35 & 18.4 \\
\hline $\mathbf{4 4 1}$ & 10 & 5.2 \\
\hline
\end{tabular}

TABLE V. CORRELATION MATRIX

\begin{tabular}{|c|c|c|c|}
\hline Variable & Social capital & Motivation & Innovation \\
\hline Social capital & 1 & & \\
\hline Motivation & $0.51^{* *}$ & 1 & \\
\hline Innovation & $0.47^{* *}$ & $0.39^{* *}$ & 1 \\
\hline Mean & 3.24 & 3.42 & 3.60 \\
\hline SD & 0.91 & 1.17 & 1.11 \\
\hline \multicolumn{4}{|r}{$* * \mathrm{p}<0.01 ; * \mathrm{p}<0.05$}
\end{tabular}

TABLE VI. ESTIMATE OF THE STANDARDIZED COEFFICIENTS OF DIRECT, INDIRECT AND TOTAL EFFECTS

\begin{tabular}{|c|c|c|c|}
\hline Path & $\begin{array}{c}\text { Direct } \\
\text { effect }\end{array}$ & $\begin{array}{c}\text { Indirect } \\
\text { effect }\end{array}$ & $\begin{array}{l}\text { Total } \\
\text { effect }\end{array}$ \\
\hline $\begin{array}{c}\text { On employee motivation vie } \\
\text { Social capital }\end{array}$ & $0.51 * *$ & - & $0.51 * *$ \\
\hline $\begin{array}{c}\text { On organizational innovation } \\
\text { vie } \\
\text { Social capital } \\
\text { Employee motivation }\end{array}$ & $\begin{array}{l}0.42 * * \\
0.59 * *\end{array}$ & $\begin{array}{c}0.30^{* *} \\
-\end{array}$ & $\begin{array}{l}0.72 * * \\
0.34 * *\end{array}$ \\
\hline
\end{tabular}

TABLE VII. FIT INDEXES OF PATH ANALYSIS MODEL

\begin{tabular}{|c|c|c|c|c|c|}
\hline$\chi \mathbf{2} / \mathbf{d f}$ & RMSEA & GFI & AGFI & CFI & NNFI \\
\hline 1.53 & 0.021 & 0.96 & 0.98 & 1 & 0.99 \\
\hline
\end{tabular}

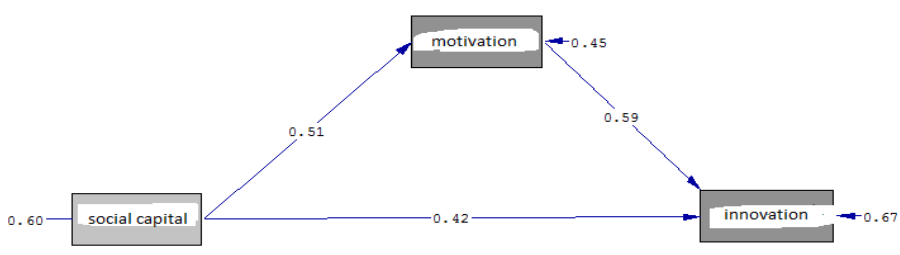

Chi-Square $=18.42, d f=12, \mathrm{P}-$ value $=0.00000, \mathrm{RMSEA}=0.021$

Fig. 3. The fitted model

\section{DISCUSSION AND CONCLUSIONS}

This study examined the effect of social capital on innovation with an emphasis on mediating role of employee motivation using path analysis. Path analysis results showed that the suggested model is well fitted to data. The results showed that social capital has a positive and significant effect on organizational innovation. This finding is consistent with the findings in [14-18]. The main proposition of social capital is that social networks (personal communications) are developed over time, underlie trust and cooperation and include actual and potential valuable resources which contribute to social relations. In fact, social capital leads people to unite, makes them work together successfully and establishes cooperation-based working relations and facilitating working practices. Therefore, increase in social capital increases organizational innovation and empowers employees, because it leads to cohesion of employees and managers and creates value-added by facilitating successful collective activities.

The results showed that employee motivation has also a significant and positive effect on organizational innovation. This finding is consistent with [19]. Enterprises with motivated employees will be better able to adapt to change. Increased employee motivation is the healthiest way to share power. This leads to self-esteem, additional energy, commitment and selfreliance in people, increased sense of participation and finally increased innovation and improved performance. High motivation of employees provides potential capacities and suggests a balanced way between applying full control of the management and staff complete freedom of action in a healthy environment. In conclusion, employee motivation has a positive effect on organizational innovation. Based on findings, the following strategies can be suggested:

This study supports the direct and indirect role of social capital in organizational innovation. Thus, SSO managers are recommended to evaluate their social capital and improve its components in the organization and increase organizational innovation. The results also showed that social capital plays an important role in increasing employee motivation. Therefore, SSO senior executives are recommended to increase employee motivation by providing training for managers and increasing their awareness of social capital. It is also recommended to establish a culture in which employees can record their work experiences. It is difficult to generalize findings. This study considered only the Social Security Organization in Tehran. Therefore, the findings cannot be generalized to other populations. Moreover, findings are based on self-reported data. It is recommended to use qualitative and mix 
methodologies in future studies to understand effective factors on organizational innovation.

\section{REFERENCES}

[1] S. Laforet, "Effects of organisational culture on organisational innovation performance in family firms", Journal of Small Business and Enterprise Development, Vol. 23, No. 2, pp. 379-407, 2016

[2] A. Monavarian, N. Asgari, Organization in the era of industry, information and knowledge, Tehran tehran university publications, 2009

[3] M. A. Mawoli, A. Y. Babandako, "An evaluation of staff motivation, dissatisfaction and job performance in an academic setting", Australian Journal of Business and Management Research, Vol. 1, No. 9, pp. 1-13, 2011

[4] A. Hecker, A. Ganter, "Organisational and Technological Innovation And The Moderating Effect Of Open Innovation Strategies", International Journal of Innovation Management, Vol. 20, No. 2, pp. 165-169, 2016

[5] T. Blokland, Networked urbanism: social capital in the city, Routledge, 2016

[6] A. Danchev, "Social capital and sustainable behavior of the firm", Industrial Management \& Data System, Vol. 106, No. 7, pp. 953-965, 2006

[7] J. Nahapiet, S. Ghoshal, "Social Capital, Intellectual Capital, and Organizational Advantage", The Academy of Management Review, Vol. 23, No. 2, pp. 242-266, 1998

[8] C. Bolino, M. Turnley, H. William, M. Bloodgood, M. James, "Citizenship behavior and the creation of social capital in organizations", Academy of Management Review, Vol. 27, No. 4, pp. 505-522, 2002

[9] M. Lazarova, S. Taylor, "Boundary less careers, social capital and knowledge management: Implications for organizational performance", Journal of Organizational Behavior, Vol. 30, No. 1, pp. 119-139, 2008

[10] D. Jimenez-Jimenez, R. Sanz Valle, M. Hernandez-Espallardo, "Fostering Innovation: The role of market orientation and organizational learning", European Journal of Innovation Management, Vol. 11, No. 3, pp. 389-412, 2008

[11] J. Ojasalo, "Management of innovation networks: a case study of different approaches", European Journal of Innovation Management, Vol. 11, No. 1, pp. 51-86, 2008

[12] C. C. Pinder, Work motivation in organizational behavior, Psychology Press 2014

[13] R. Dwivedula, C. N. Bredillet, R. Müller, "Work Motivation in Temporary Organizations: A Review of Literature Grounded in Job Design Perspective", In: Leadership, Innovation and Entrepreneurship as Driving Forces of the Global Economy, pp. 609-618, Springer International Publishing, 2017

[14] K. Abili, H. Faraji-Dehsorkhi, K. Shateri, A. Youzbashi, "The relationship between social capital and organizational innovation in tehran university employees", Journal of Shahed University, 2010

[15] M. Rezvani, M. T. Toghrai, "The role of social capital on organizational innovation in knowledge-based companies", Transformation Management, Vol. 3, No. 6, pp. 28-33, 2011

[16] G. Schiuma, A. Lerro, "Knowledge-based capital in building regional innovation capacity", Journal of Knowledge Management, Vol. 12, No. 5, pp. 121-136, 2008

[17] M. Zerenler, S. Burak Hasiloglu, M. Sezgin, "Intellectual Capital and innovation Performance: Empirical evidence in the turkish automotive supplier", Journal of Technology Management \& Innovation, Vol. 3, No. 4, pp. 31-40, 2008

[18] R. Ngah, A. R. Ibrahim, "The relationship of intellectual capital, Innovation and organizational performance: A preliminary study in malaysian SMEs", International Journal of Management Innovation Systems, Vol. 1, No. 1. 2009

[19] C. R. Leana, F. K. Pil, "Social capital and organizational performance: Evidence from urban public school", Organizational Science, Vol. 17, No. 3, pp. 353-366, 2006 